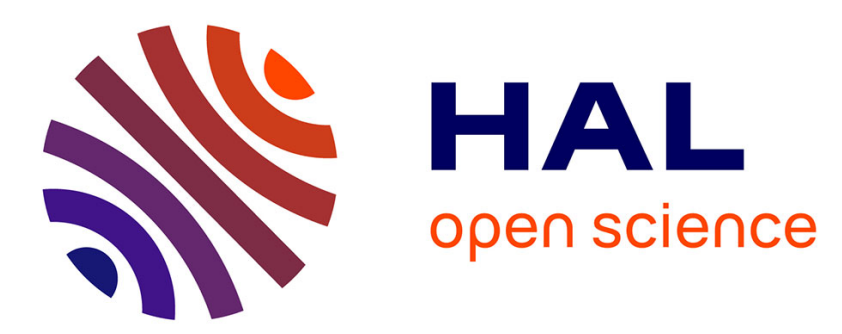

\title{
Condition Monitoring of Wind Turbines Based on Amplitude Demodulation
}

\author{
Yassine Amirat, Vincent V. Choqueuse, Mohamed Benbouzid
}

\section{To cite this version:}

Yassine Amirat, Vincent V. Choqueuse, Mohamed Benbouzid. Condition Monitoring of Wind Turbines Based on Amplitude Demodulation. IEEE Energy Conversion Congress and Exposition (ECCE), 2010, Sep 2010, Atlanta, United States. pp.2417 - 2421, 10.1109/ECCE.2010.5617914 . hal-00532620

\section{HAL Id: hal-00532620 https://hal.science/hal-00532620}

Submitted on 4 Nov 2010

HAL is a multi-disciplinary open access archive for the deposit and dissemination of scientific research documents, whether they are published or not. The documents may come from teaching and research institutions in France or abroad, or from public or private research centers.
L'archive ouverte pluridisciplinaire HAL, est destinée au dépôt et à la diffusion de documents scientifiques de niveau recherche, publiés ou non, émanant des établissements d'enseignement et de recherche français ou étrangers, des laboratoires publics ou privés. 


\section{Condition Monitoring of Wind Turbines Based on Amplitude Demodulation}

\author{
Yassine Amirat \\ University of Brest, LBMS EA 4325 \\ Rue de Kergoat, CS 93837 \\ 29238 Brest Cedex 03, FRANCE \\ Email: yassine.amirat@univ-brest.fr
}

\author{
Vincent Choqueuse \\ University of Brest, LBMS EA 4325 \\ Rue de Kergoat, CS 93837 \\ 29238 Brest Cedex 03, FRANCE
}

Email: vincent.choqueuse@univ-brest.fr

\author{
Mohamed Benbouzid \\ University of Brest, LBMS EA 4325 \\ Rue de Kergoat, CS 93837 \\ 29238 Brest Cedex 03, FRANCE \\ Email: mohamed.benbouzid@univ-brest.fr
}

\begin{abstract}
Wind energy conversion systems (WECS) have become a focal point in the research of renewable energy sources. In order to make wind turbine reliable and competitive, it is important to reduce the operational and maintenance costs. The most efficient way to reduce it relies on condition monitoring and fault diagnostics. This paper proposes a new fault detector based on the amplitude demodulation of the three-phase stator current. Simulations show that this low-complexity method is well suited for stationary or non-stationary behavior.
\end{abstract}

Index Terms-Wind turbine, Fault Detection, Bearings, Signal Processing, Amplitude Modulation

\section{INTRODUCTION}

Wind energy conversion system is the fastest-growing source of new electric generation technologies in the world and it is expected to remain so for some time. In order to be more reliable and competitive than classical power generation systems and due to geographical location of WECS, it is important to prevent failure and to reduce maintenance cost. To fulfill this task, condition monitoring systems with integrated fault detection algorithms must be implemented. In this paper, the detection algorithm is based on the stator current signal. Many tools have been proposed in the literature to monitor the condition of an electrical machine from the stator current [1][3]. To detect a failure, stationary signal processing tools, like the Fast Fourier Transform (FFT) or MUltiple SIgnal Classification (MUSIC) [4], are commonly used. However, these tools are inappropriate for wind turbines since these systems have predominantly transient behavior. Under non-stationary behavior, recent papers describe algorithms based on timefrequency representations [5]-[7], or time-scale analysis [8][10]. Nevertheless, theses techniques have drawbacks such as high complexity, poor resolution and/or may suffer from artifacts (cross term,aliasing...). Recently, it has been demonstrated that many failures lead to stator current modulation [5], [6], [11]-[13]. Therefore, a natural low-complexity approach to detect a failure relies on the stator current demodulation. In this study, we focus on mechanical failures that lead to stator current amplitude modulation (AM). These include air gap eccentricity and rotor asymmetry faults [6], [12]. To detect a failure, we propose a new detector based on the variance of the demodulated current. This paper is organized as follows. Section II presents the stator current signal model for healthy and faulty wind turbines. Section III presents two amplitude demodulation techniques and section IV describes a new fault detector based on amplitude demodulation. Finally, the performances of the proposed methods are reported and compared in section $\mathrm{V}$.

\section{Signal MODEL}

This work focuses on mechanical failures that lead to stator current amplitude modulation (AM). For three-phase generator, the stator currents $i_{k}(n)(k=0,1,2)$ can be described into a discrete form as:

$$
i_{k}(n)=a_{k}(n) \cdot \cos \left(\omega n-\phi_{k}\right)
$$

where $n=0, \cdots, N-1$ is the sample index, $N$ is the number of received samples and $\phi_{k}=2 k \pi / 3(k=0,1,2)$ is the phase parameter. In equation (1), frequency $\omega$ is equal to $2 \pi f / F_{e}$, where $f$ and $F_{e}$ are the supply and sampling frequency, respectively. Amplitude $a_{k}(n)$ is related to the fault as follows

- for healthy machine, $a_{k}(n)$ is constant (No AM).

- for faulty machine, $a_{k}(n)$ varies with time (AM).

In most study, a balanced system is assumed. Balanced system satisfies $\sum_{k=0}^{2} i_{k}(n)=0$ which also implies that the $a_{k}(n)$ are equal i.e $a_{k}(n)=a(n) \forall k=0,1,2$. However, one should note that practical systems rarely have perfectly balanced load in all three phases. Furthermore, failure usually does not affect each of the three phase equally. In this study, the condition $a_{k}(n)=a(n)$ is relaxed and unbalanced system are also considered.

\section{Amplitude Demodulation TechniQues}

\section{A. Concordia Transform (CT)}

The Concordia Transform (CT) converts the 3 phase current to Park's space vector components $i_{\alpha}(n)$ and $i_{\beta}(n)$. The Park components are given by:

$$
\left[\begin{array}{c}
i_{\alpha}(n) \\
i_{\beta}(n)
\end{array}\right]=\left[\begin{array}{ccc}
\frac{2}{3} & -\frac{1}{3} & -\frac{1}{3} \\
0 & \frac{1}{\sqrt{3}} & -\frac{1}{\sqrt{3}}
\end{array}\right]\left[\begin{array}{c}
i_{0}(n) \\
i_{1}(n) \\
i_{2}(n)
\end{array}\right]
$$


Several fault detectors based on CT have been proposed in literature [14]-[19]. Recently, it has been shown that CT can be viewed as a demodulation technique for balanced system [19]. Indeed, under the assumption that the system is balanced, the Park components can be expressed as:

$$
\begin{aligned}
i_{\alpha}(n) & =a(n) \cdot \cos (\omega n) \\
i_{\beta}(n) & =a(n) \cdot \sin (\omega n)
\end{aligned}
$$

Then, the amplitude can be estimated by:

$$
|a(n)|=\sqrt{i_{\alpha}^{2}(n)+i_{\beta}^{2}(n)}
$$

Therefore, if the system is balanced, CT can be considered as a low-complexity demodulating technique. However, if the system is unbalanced, equation (3) is no longer valid and $|a(n)|$ depends on the three modulating signals $a_{0}(n), a_{1}(n)$ and $a_{2}(n)$.

\section{B. Hilbert Transform (HT)}

A standard approach to extract the envelope $a_{k}(n)$ from $i_{k}(n)$ is based on the Hilbert transform. Let us consider a discrete sequence $i_{k}(n)$. The Discrete Hilbert Transform (DHT) of $i_{k}(n)$ is given by [20]:

$$
\mathcal{H}\left[i_{k}(n)\right]=\mathcal{F}^{-1}\left\{\mathcal{F}\left\{i_{k}(n)\right\} \cdot u(n)\right\}
$$

where $\mathcal{F}\{$.$\} and \mathcal{F}^{-1}\{$.$\} correspond to the Fast Fourier$ Transform (FFT) and Inverse FFT (IFFT), respectively, and where $u(n)$ is defined as:

$$
u(n)= \begin{cases}1, & n=0, \frac{N}{2} \\ 2, & n=1,2, \ldots, \frac{N}{2}-1 \\ 0, & n=\frac{N}{2}-1, \cdots, N-1\end{cases}
$$

Let us define the analytic signal of $i_{k}(t)$, denoted $z_{k}(n)$, as:

$$
z_{k}(n)=i_{k}(n)+j \mathcal{H}\left[i_{k}(n)\right]
$$

Using signal model (1), the amplitude envelope can be estimated by [20]:

$$
\left|a_{k}(n)\right| \approx\left|z_{k}(n)\right|
$$

In comparison to CT, HT can be used for amplitude demodulation even if the system is unbalanced since it is computed from one-phase only. However, the major drawback of HT lies on the associated computation cost since this method is more complex than CT. Moreover, HT can lead to edge effects problem at the beginning and end of $\left|a_{k}(n)\right|$ whereas CT is free from this artifact.

\section{FAult Detector}

Several fault detectors based on amplitude demodulation have been proposed in literature. These includes Hidden Markov Model (HMM) [21], Neural Networks (ANN) [14], Fuzzy Logic [18]. However, most of these approaches employs unnecessary complicated classifier. Furthermore these methods assume that a training database is available, which can be difficult to obtain in some scenario. In this section, we propose a low complexity detector which does not require any training set. The detector is based on the variance of $|a(n)|$ or $\left|a_{k}(n)\right|$.

\section{A. Fault Detector After CT Demodulation}

After applying CT, envelope $|a(n)|$ is extracted with (3). Then, we propose to compute the variance of $|a(n)|$ to detect a fault. This statistic criterion, denoted $\sigma_{C}^{2}$, is given by:

$$
\sigma_{C}^{2}=\frac{1}{N} \sum_{n=0}^{N-1}(|a(n)|-\mu)^{2}
$$

where $\mu$ is the average of $|a(n)|$ i.e.

$$
\mu=\frac{1}{N} \sum_{n=0}^{N-1}|a(n)|
$$

The variance $\sigma_{C}^{2}$ measures the deviation of the amplitude around its mean $\mu$. This criterion can be used to detect amplitude modulation for balanced system. Indeed, if no fault is present, $|a(n)|$ is constant and so $|a(n)|=\mu$. Using (8), it follows that $\sigma_{C}^{2}=0$. On the contrary, for healthy machine $|a(n)|$ is not constant, which also implies $\sigma_{C}^{2}>0$. Therefore, we can propose a simple hypothesis test for failure detection under balanced assumption:

- If $\sigma_{C}^{2}<\gamma_{C}$, the generator is healthy.

- If $\sigma_{C}^{2}>\gamma_{C}$, the generator is faulty.

where $\gamma_{C}$ is a threshold which can be set subjectively. For unbalanced system, one should note that this simple hypothesis test is no longer valid since $\sigma_{C}^{2}$ is not necessary equal to 0 for healthy machine.

\section{B. Fault Detector Based on HT Demodulation}

After applying HT independently on the three currents, we propose to exploit the information given by the three extracted envelopes. To avoid the edge effect problem of HT, each envelope is truncated by removing $\alpha$ samples at the beginning and at the end of $\left|a_{k}(n)\right|$. The proposed criterion, $\sigma_{H}^{2}$, is then equal to:

$$
\sigma_{H}^{2}=\frac{1}{3(N-2 \alpha)}\left(\sum_{k=0}^{2} \sum_{n=\alpha}^{N-\alpha-1}\left(\left|a_{k}(n)\right|-\mu_{k}\right)^{2}\right)
$$

where $\mu_{k}$ is the average of $\left|a_{k}(n)\right|$, i.e.

$$
\mu_{k}=\frac{1}{(N-2 \alpha)} \sum_{n=\alpha}^{N-\alpha-1}\left|a_{k}(n)\right|
$$

In (10), the average is used to make the criteria $\sigma_{H}^{2}$ and $\sigma_{C}^{2}$ equivalent for balanced system. Indeed if $a_{k}(n)=a(n)$ for all $k=\{0,1,3\}$ and if the edge effects problems are neglected, then it can be shown that $\sigma_{H}^{2}=\sigma_{C}^{2}$ with $\alpha=0$. This property no longer holds for unbalanced system. For healthy unbalanced system, envelopes $a_{k}(n)$ are different but they are all constant. It follows that $\left|a_{0}(n)\right|=\mu_{0}$, $\left|a_{1}(n)\right|=\mu_{1}$ and $\left|a_{2}(n)\right|=\mu_{2}$ and so $\sigma_{H}^{2}=0$. Therefore, we propose a simple hypothesis test to detect a fault under unbalanced condition: 


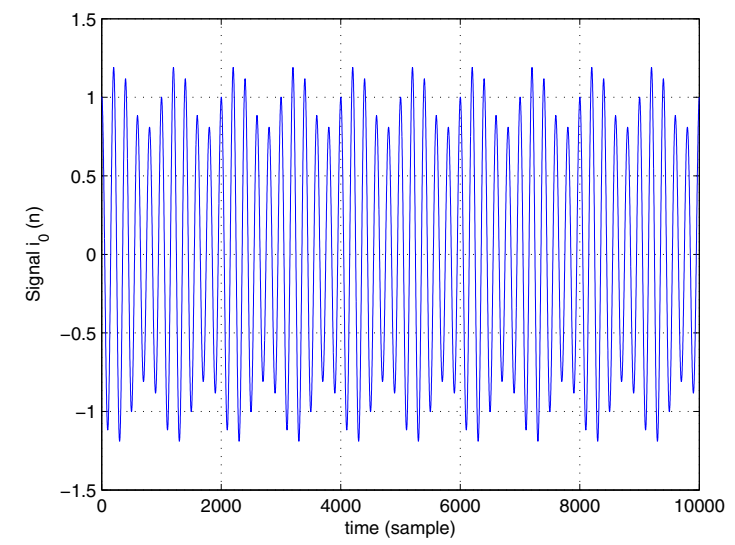

Fig. 1. Time representation of the stator current $i_{0}(n)$ for a faulty machine $(\beta=0.2)$.

- If $\sigma_{H}^{2}<\gamma_{H}$, the generator is healthy.

- If $\sigma_{H}^{2}>\gamma_{H}$, the generator is faulty.

where $\gamma_{H}$ is a threshold which can be set subjectively. One should remark that this second hypothesis test is more powerful since it can be employed for balanced and unbalanced systems.

\section{EXPERIMENTAL RESULTS}

In this section, the result of several simulations is presented to compare the performance of the proposed fault detectors. For each simulation, the amplitude envelope is estimated through CT or HT. Then, depending of the demodulation technique, criteria $\sigma_{C}^{2}$ or $\sigma_{H}^{2}$ are computed to detect a failure. The simulation have been performed for healthy and faulty machines.

\section{A. Synthetic Signals}

In this subsection, several simulations have been performed with AM synthetic signals, which are given by [6]:

$$
i_{k}(n)=\underbrace{\left(1+\beta \sin \left(\omega_{2} n+\psi_{k}\right)\right)}_{a_{k}(n)} \cdot \cos \left(\omega n+\phi_{k}\right)
$$

where $\beta$ is a fault index which is equal to 0 for healthy machines and $>0$ for faulty ones. The parameters $\psi_{k}$ and $\gamma_{k}$ are calibrated according to the balanced assumption. If the system is balanced, $\psi_{k}=\psi(k=0,1,2)$ whereas $\psi_{k}$ depends on $k$ for unbalanced system. Simulations have been run with a sampling frequency $F e=10 \mathrm{kHz}$ during 1 second with $\omega=0.1534 \mathrm{rad} / \mathrm{s}$ (supply frequency $f=50 \mathrm{~Hz}$ ) and $\omega_{2}=0.0307 \mathrm{rad} / \mathrm{s}\left(f_{2}=10 \mathrm{~Hz}\right)$. The fault index has been set to $\beta=0.2$ to simulate faulty machine (see figure 1 for time representation of $\left.i_{0}(n)\right)$. After HT demodulation, $\alpha=10$ samples have been removed at the beginning and at the end of $\left|a_{k}(n)\right|$ to avoid edge effect problems. One should note that a larger $\alpha$ can make the criterion $\sigma_{H}$ more sensible to noise or other sources of disturbance.

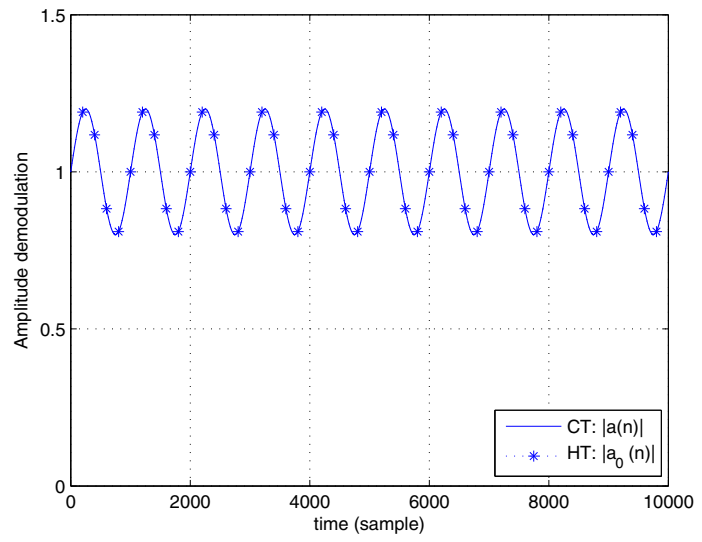

Fig. 2. Balanced system- Faulty machine. Time representation of the envelopes after CT and HT demodulation $(\beta=0.2)$.

1) Balanced system $(\psi=0)$ : For balanced system, the amplitude envelopes are the same for the three currents. Figure 2 displays $|a(n)|$ and $\left|a_{0}(n)\right|$ extracted with HT and $\mathrm{CT}$, respectively, for a faulty machine. One can notice that the two demodulation techniques lead to the same envelope. Table I shows the values of the fault detector criteria $\sigma_{C}^{2}$ and $\sigma_{H}^{2}$ for faulty and healthy machine. The two criteria lead to similar results, indeed $\sigma_{C}^{2}=\sigma_{H}^{2}=0$ for healthy machine and $\sigma_{C}^{2}=\sigma_{H}^{2}=0.020$ for faulty ones. Therefore, a fault can be easily detected in this context by setting the threshold of the fault detector to $\gamma_{C}=\gamma_{H}=0.010$. From a practical point of view, one should note that $\mathrm{CT}$ demodulation must be preferred for balanced system since it has a lower complexity than HT and does not suffer from edge effects problems.

TABLE I

FAULT DETECTOR FOR HEALTHY AND FAULTY GENERATORS.

\begin{tabular}{|c|c|c|c|}
\hline \multirow{2}{*}{ System } & \multirow{2}{*}{ Demodulation } & \multicolumn{2}{|c|}{ Fault detector } \\
& & Healthy case & Faulty case \\
\hline Balanced \& & CT & $\sigma_{C}^{2}=0.000$ & $\sigma_{C}^{2}=0.020$ \\
Stationary & HT & $\sigma_{H}^{2}=0.000$ & $\sigma_{H}^{2}=0.020$ \\
\hline Unbalanced \& & CT & $\sigma_{C}^{2}=0.000$ & $\sigma_{C}^{2}=0.005$ \\
Stationary & HT & $\sigma_{H}^{2}=0.000$ & $\sigma_{H}^{2}=0.020$ \\
\hline Unbalanced \& & CT & $\sigma_{C}^{2}=0.000$ & $\sigma_{C}^{2}=0.005$ \\
Non-stationary & HT & $\sigma_{H}^{2}=0.000$ & $\sigma_{H}^{2}=0.020$ \\
\hline
\end{tabular}

2) Unbalanced system $\left(\psi_{0}=0, \psi_{1}=2 \pi / 3, \psi_{2}=-2 \pi / 3\right)$ : Let us simulate a system which is balanced under healthy condition and unbalanced under faulty condition. Figure 3 displays $|a(n)|$ and the envelope $\left|a_{0}(n)\right|$ extracted with CT and HT, respectively, for a faulty generator. As expected, CT is not able to demodulate the signals. Table I presents the values of the fault detector criterion $\sigma_{C}^{2}$ and $\sigma_{H}^{2}$ under healthy and faulty conditions. In our simulations, criterion $\sigma_{H}^{2}$ leads to the same values for balanced and unbalanced system whereas the value of $\sigma_{H}^{2}$ decreases under unbalanced condition. One can notice that the difference between healthy and faulty case is larger for $\sigma_{H}^{2}$. For fault detection, an hypothesis-test threshold equal to $\gamma_{C}=0.0025$ for $\sigma_{C}^{2}$ and 


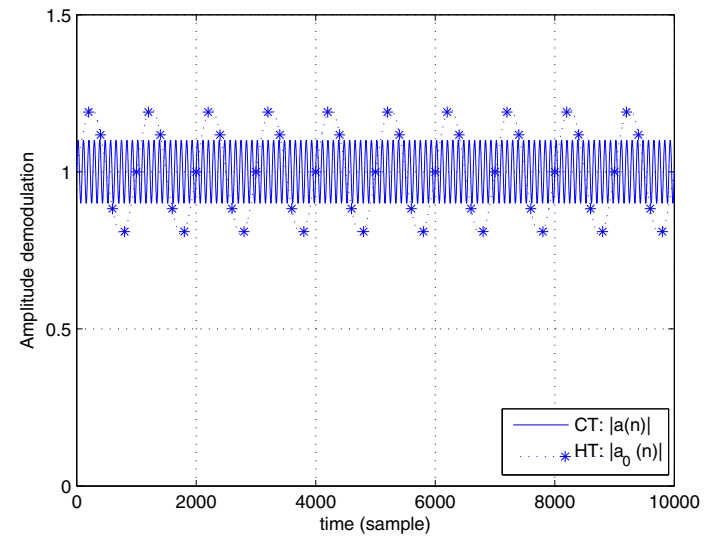

Fig. 3. Non-balanced system - Faulty machine. Time representation of the envelopes after CT and HT demodulation $(\beta=0.2)$.

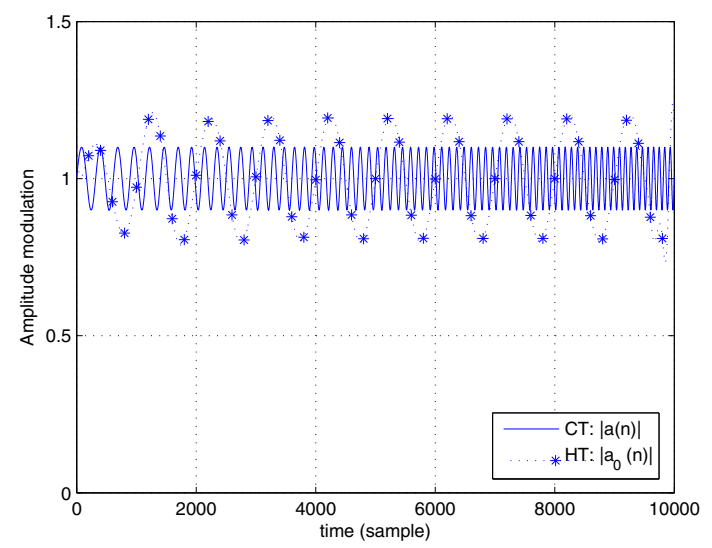

Fig. 4. Non-balanced system under non-stationary condition- Faulty machine. Time representation of the envelopes after CT and HT demodulation $(\beta=$ $0.2)$.

$\gamma_{H}=0.010$ for $\sigma_{H}^{2}$ lead to correct results in this context.

3) Unbalanced system $\left(\psi_{0}=0, \psi_{1}=2 \pi / 3, \psi_{2}=-2 \pi / 3\right)$ under nonstationary supply frequency: To simulate nonstationary environment, supply frequency $f$ is assumed to vary linearly between $10 \mathrm{~Hz}$ and $50 \mathrm{~Hz}$ i.e.

$$
\omega(n)=\frac{2 \pi}{F e}\left(\frac{40}{2 N} n+10\right)
$$

Figure 4 displays $|a(n)|$ and the envelope $\left|a_{0}(n)\right|$ extracted with CT and HT, respectively, for a faulty machine under non-stationary supply frequency. As edge effect problem occurs for HT (see Fig.4), $\alpha=500$ samples have been removed at the beginning and at the end of $\left|a_{k}(n)\right|$. Table I presents the values of the fault detector criterion $\sigma_{C}^{2}$ and $\sigma_{H}^{2}$. One should note that the values $\sigma_{C}^{2}$ and $\sigma_{H}^{2}$ do not depend on the stationary assumption in our context. Therefore, fault detectors based on amplitude demodulation seem to be well-suited for non-stationary scenario. In particular,

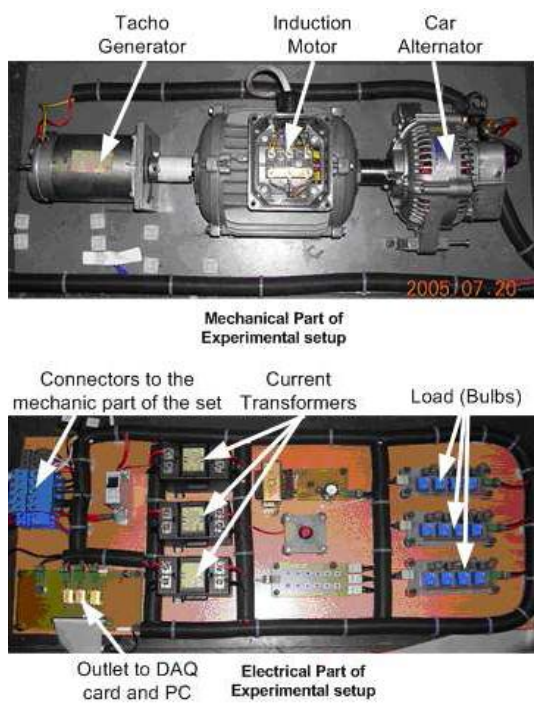

Fig. 5. Experimental setup.

these detectors do not need to employ complicated timefrequency representations, such as spectrogram, Wigner-Ville representation, that suffer from artifact or poor resolution.

\section{B. Experimental signals}

In this section, the result of our approach is presented with experimental signals. Fig.5 describes the experimental setup which is composed of a tacho-generator, a three-phase induction motor and an alternator. The experimental setup is operated in the motor configuration for experimental easiness. The alternator is a three-phase synchronous machine with a regulator and a rectifier circuit that stabilize the output voltage at 12 VDC. The advantage of using a car alternator instead of DC generator is obtaining constant output voltage at various speeds. The induction motor could be identically loaded at different speeds. Moreover, if the induction motor is supplied from the network, motor current will have time harmonic components as well as bearing fault harmonics. This makes it harder to determine the bearing failure effect on the stator current and therefore complicates the fault detection process. For these reasons, the induction motor is fed by an alternator. By this way, supply harmonics effects are eliminated and only bearing failure effects could be observed on the stator current. The tested induction motor has the following rated parameters: $0.75 \mathrm{~kW}, 220 / 380 \mathrm{~V}, 1.95 / 3.4 \mathrm{~A}, 2780 \mathrm{rpm}, 50 \mathrm{~Hz}, 2$ poles, Yconnected. It has two 6204.2ZR type bearings. From the bearing data sheet the following parameters are obtained: The outside diameter is $47 \mathrm{~mm}$ and inside one is $20 \mathrm{~mm}$. Assuming that the inner and the outer races have the same thickness gives the pitch diameter $D_{P}=31.85 \mathrm{~mm}$. The bearing has eight balls $(\mathrm{N}=8)$ with an approximate diameter of $D_{B}=12 \mathrm{~mm}$ and a contact angle $\theta=0^{\circ}$. The faulty system is corrupted by a ball deterioration. Statistics of $i_{k}(n)$ reveal that the currents 


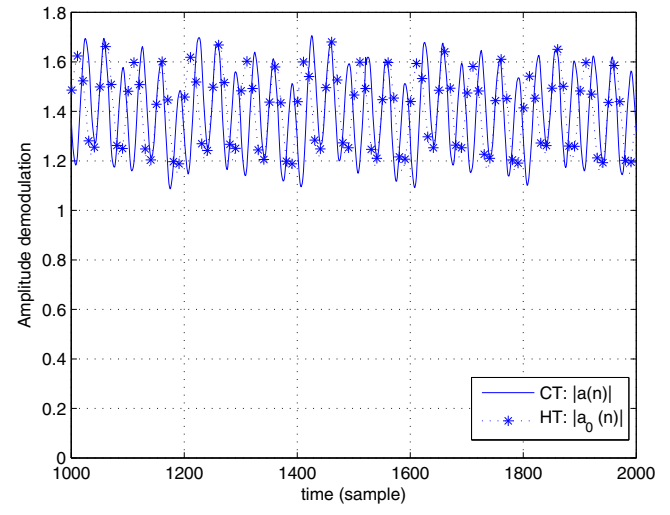

Fig. 6. Faulty machine generator: Time representation of the envelopes after CT and HT demodulation.

TABLE II

NON-BALANCED SYSTEM: FAULT DETECTOR FOR HEALTHY AND FAULTY GENERATORS.

\begin{tabular}{|c|c|c|}
\hline & \multicolumn{2}{|c|}{ Fault detector } \\
\hline Demodulation & Healthy case & Faulty case \\
\hline CT & $\sigma_{C}^{2}=0.059$ & $\sigma_{C}^{2}=0.095$ \\
HT & $\sigma_{H}^{2}=0.039$ & $\sigma_{H}^{2}=0.093$ \\
\hline
\end{tabular}

are not perfectly balanced even for the healthy system. Indeed, the HT-based criterion is expected to give better results than the CT-based one. Figure 6 displays the envelopes $|a(n)|$ and $\left|a_{0}(n)\right|$ for a faulty machine after CT and HT demodulation, respectively. Table II shows the values of $\sigma_{C}^{2}$ and $\sigma_{H}^{2}$ for the faulty and healthy machine. As the system is not perfectly balanced, $\sigma_{C}^{2}$ and $\sigma_{H}^{2}$ are not equal to 0 for healthy machine. However, it can be notice that $\sigma_{C}^{2}$ is bigger than $\sigma_{H}^{2}$ under healthy condition. Under faulty condition, $\sigma_{C}^{2}$ is multiplied by 1.61 as compared to the healthy case, whereas $\sigma_{H}^{2}$ is multiplied by 2.38 . Therefore, our experimental simulation corroborates the fact that it is easier to detect a fault with $\sigma_{H}^{2}$ than with $\sigma_{C}^{2}$ under unbalanced condition.

\section{CONCLUSION}

An amplitude demodulation approach has been proposed for fault detection. First, the received currents are demodulated using Concordia Transform (CT) or Hilbert Transform (HT). Then, an hypothesis test based on the statistical variance of the demodulated envelope is performed to discriminate between healthy and faulty generators. The result of several simulations have shown that the proposed method performs well in stationary and non-stationary scenario. Furthermore results have shown that, even if CT is computationally attractive compared to HT, this low complexity demodulation technique can be inappropriate for the diagnosis of unbalanced systems.

\section{REFERENCES}

[1] M. Benbouzid, "Bibliography on induction motors faults detection and diagnosis," IEEE Trans. Energy Conversion, vol. 14, no. 4, pp. 10651074, 1999.
[2] — , "A review of induction motors signature analysis as a medium for faults detection," IEEE Trans. Industrial Electronics, vol. 47, no. 5, pp. 984-993, 2000.

[3] S. Nandi, H. Toliyat, and L. Xiaodong, "Condition monitoring and fault diagnosis of electrical motors - a review," IEEE Trans. Energy Conversion, vol. 20, no. 4, pp. 719-729, 2005.

[4] S. Kia, H. Henao, and G. Capolino, "A high-resolution frequency estimation method for three-phase induction machine fault detection," IEEE Transactions on Industrial Electronics, vol. 54, no. 4, 2007.

[5] M. Blodt, D. Bonacci, J. Regnier, M. Chabert, and J. Faucher, "Online monitoring of mechanical faults in variable-speed induction motor drives using the wigner distribution," IEEE Transactions on Industrial Electronics, vol. 55, no. 2, pp. 522-533, 2008.

[6] M. Blodt, J. Regnier, and J. Faucher, "Distinguishing load torque oscillations and eccentricity faults in induction motors using stator current wigner distributions," IEEE Transactions on Industry Applications, vol. 45, no. 6, pp. 1991-2000, 2009.

[7] J. Antonino-Daviu, M. Riera-Guasp, M. Pineda-Sanchez, and R. Prez, "A critical comparison between DWT and Hilbert-Huang-based methods for the diagnosis of rotor bar failures in induction machines," IEEE Transactions on Industry Applications, vol. 45, no. 5, 2009.

[8] J.Cusido, L. Romeral, J. Ortega, J. Rosero, and A. Espinosa, "Fault detection in induction machines using power spectral density in wavelet decomposition," IEEE Transactions on Industrial Electronics, vol. 55, no. 2, pp. 633-643, 2008.

[9] M. Riera-Guasp, J. Antonio-Daviu, J. Roger-Folch, and M. P. M. Palomares, "The use of the wavelet approximation signal as a tool for the diagnosis of rotor bar failure," IEEE Transactions on Industry Applications, vol. 44, no. 3, 2008.

[10] S. Kia, H. Henao, and G. Capolino, "Diagnosis of broken-bar fault in induction machines using discrete wavelet transform without slip estimation," IEEE Transactions on Industry Applications, vol. 45, no. 4, pp. 1395-1404, 2009.

[11] M. Blodt, M. Chabert, J. Regnier, and J. Faucher, "Mechanical load fault detection in induction motors by stator current time-frequency analysis," IEEE Transactions on Industry Applications, vol. 42, no. 6, pp. 1454$1463,2006$.

[12] I. Jaksch and P. Fuchs, "Rotor cage faults detection in induction motors by motor current demodulation analysis," in SDEMPED, Cracow, Poland, 2005, pp. 247-252.

[13] S. Kia, H. Henao, and G. Capolino, "Analytical and experimental study of gearbox mechanical effect on the induction machine stator current signature," IEEE Transactions on Industry Applications, vol. 45, no. 4, pp. 1405-1415, 2009.

[14] H. Nejjari and M. Benbouzid, "Monitoring and diagnosis of induction motors electrical faults using a current park's vector pattern learning approach," IEEE Transactions on Industry Applications, vol. 36, no. 3, pp. 730-735, 2000.

[15] S. Cruz and A. M. Cardoso, "Stator winding fault diagnosis in threephase synchronous and asynchronous motors, by the extended park's vector approach,' IEEE Transactions on Industry Applications, vol. 37, no. 5, pp. 1227-1233, 2001.

[16] I. Jaksch, "Fault diagnosis of three-phase induction motors using envelope analysis," in SDEMPED, Atlanta, USA, 2003, pp. 289-293.

[17] D. Diallo, M. Benbouzid, D. Hamad, and X. Pierre, "Fault detection and diagnosis in an induction machine drive: A pattern recognition approach based on concordia stator mean current vector," IEEE Transactions on Energy Conversion, vol. 20, no. 3, pp. 512-519, 2005.

[18] I. Onel and M. Benbouzid, "Induction motor bearing failure detection and diagnosis: Park and concordia transform approaches comparative study," IEEE/ASME Transactions on mechatronics, vol. 13, no. 2, pp. 257-262, 2008.

[19] B. Trajin, M. Chabert, J. Regnier, and J. Faucher, "Hilbert versus concordia transform for three phase machine stator current time-frequency monitoring," Mechanical systems \& signal processing, vol. 23 , no. 8 , pp. 2648-2657, 2009.

[20] A. Oppenheim, R. Schafer, and W. Padgett, Discrete-Time Signal Processing, 3rd ed. Prentice Hall, 2009.

[21] H. Ocak and K. Loparo, "A new bearing fault detection and diagnosis schema based on hidden markov modeling of vibration signals," in IEEE ICASSP, Salt Lake City, USA, 2001, pp. 3141-3144. 